\title{
Ultrasound-Assisted Extraction of Phenolic Compounds from Mango (Mangifera indica cv. Chok Anan) Peel and Its Inhibitory Effect on Enzymatic Browning of Potato Puree
}

\section{Chotika Jirasuteeruk and Chockchai Theerakulkait*®}

Department of Food Science and Technology, Faculty of Agro-Industry, Kasetsart University, 50 Ngam Wong Wan Rd, Lat Yao, Chatuchak, 10900 Bangkok, Thailand

Received: 15 February 2018 Accepted: 7 August 2019
*Corresponding author:

Phone: +6625625032

Fax: +6625625021

E-mail: fagicct@ku.ac.th

\section{SUMMARY}

Enzymatic browning is a serious quality deterioration of fresh-cut fruits and vegetables. Recently, consumers and fruit and vegetable industrial processors have demanded the use of natural antibrowning agents to replace the use of chemicals. Mango (Mangifera indica cv. Chok Anan) peel was prepared in the form of mango peel liquid nitrogen powder. This included extraction by ultrasound or ultrasound combined with stirring. The total phenolic content of mango peel liquid nitrogen powder extract (further in the text: mango peel extract) was the highest after the extraction for $15 \mathrm{~min}$ using ultrasound followed by stirring for $15 \mathrm{~min}$. The browning value of potato puree treated with mango peel extract was lower, while its $L^{*}$ value and the hue angle were larger than of samples treated with ascorbic or citric acids during storage for $6 \mathrm{~h}$. Mango peel extract had a competitive inhibitory effect on potato polyphenol oxidase (PPO), which was larger than either ascorbic or citric acid. Its $I C_{50}$ value was $0.3 \mathrm{mg} / \mathrm{mL}$. Mangiferin, protocatechuic and gallic acid found in mango peel extract had high inhibitory effect on potato PPO, making mango peel a potential natural source of enzymatic browning inhibitor.

Key words: mango peel, polyphenol oxidase, potato, browning inhibition

\section{INTRODUCTION}

Mango (Mangifera indica L.) fruit is an economic crop in over 100 countries and its global production is rising (1). It is a seasonal fruit and is a high-volume export of Thailand. Several well-known cultivars of mango are grown in this country. These include Nam Dok Mai, Chok Anan and Kaew. Chok Anan cultivar is well known in the mango processing industry (2). Mango is processed into products including puree, fruit leather, nectar, pickles and canned slices (3). Its peel is a major waste of industrial processing or fresh fruit. It comprises $7-24 \%$ of the total mass of mango fruit (3). Several researchers have found that mango peel is a major source of pectin, proteins and carbohydrates, and that it also contains phenolic compounds (mangiferin, quercetin, rhamnetin, ellagic acid, kaempferol, etc.), which are important antioxidants. These can be used as functional food or nutraceuticals (4). The presence of phenolic compounds in the diet may provide a defensive activity against some chronic degenerative diseases that entail oxidative stress (5).

Potato (Solanum tuberosum) is the fourth most significant food crop worldwide. It is used for both animal feed and human food production (6). It can be prepared in various ways. Potato handling, storage and processing can cause tissue damage and black and/ or brown discoloration via an enzymatic browning reaction involving polyphenol oxidase (PPO) (7). Previous studies revealed that the phenolic compounds from rice bran extract can effectively inhibit enzymatic browning in potato (8-10).

PPO is the main enzyme that catalyzes the browning reaction in fresh-cut fruits (11). In the presence of oxygen, PPO catalyzes the oxidation of $o$-diphenols to o-quinone and the hydroxylation of monophenols to $o$-diphenol, which can undergo self-polymerization or interact with other compounds that subsequently form brown pigments (12). Enzymatic browning is a significant problem with fresh-cut fruits and vegetables such as apples, 
bananas, grapes, potatoes, lettuce and other leafy vegetables (13). Browning usually degrades the quality of fruit and vegetable due to colour changes which reduce their market value (14). Many methods are used to inhibit PPO activity. Generally, physical methods have been employed such as heating and ultrasound as well as the use of chemicals such as ascorbic and citric acids, and sulfites. Sulfites are a more effective browning inhibitor, but it has been reported that they may affect human health (15). Therefore, there is a consumer demand for the use natural PPO inhibitors to replace the synthetic compounds. Mango peel is a waste product from the fruit processing industry that is a rich source of antioxidative phenolic compounds $(3,4)$. Therefore, the goal of the present work is to examine the inhibitory effects of mango peel extract using ultrasound-assisted extraction and its phenolic compounds as natural inhibitors of enzymatic browning in potato puree.

\section{MATERIALS AND METHODS}

\section{Materials and chemicals}

Potatoes (Solanum tuberosum L.) were bought from a local shop in Bangkok, Thailand. Mango (Mangifera indica L. cv. Chok Anan) peel was obtained from the Peace Canning (1958) Co. Ltd., Chiangmai, Thailand. We obtained Folin-Ciocalteu phenol reagent from Merck (Darmstadt, Germany). Triton X-100 and L-ascorbic acid were bought from Fluka (Steinheim, Germany). Sodium carbonate, polyvinylpyrrolidone, catechol, citric acid, sodium disulfite, gallic and protocatechuic acids used as a phenolic acid standard were obtained from Sigma-Aldrich, Merck, Steinheim, Germany. Mangiferin and ellagic acid were obtained from Sigma-Aldrich, Merck, Buchs, Switzerland. Acetic acid, and methanol were obtained from Merck (Darmstadt, Germany). Acetonitrile was obtained from Mallinckrodt (Phillipsburg, NJ, USA) and used in HPLC analyses.

\section{Preparation of mango peel liquid nitrogen powder}

Mango peel was blended with liquid nitrogen in a blender (34B299; Waring, Stamford, CT, USA) until a mango peel liquid nitrogen powder was obtained using the same method as the one used to prepare pineapple shell powder (16). The powder was stored at $-18^{\circ} \mathrm{C}$ until use.

\section{Ultrasound-assisted extraction of phenolic compounds from mango peel powder}

The mango peel powder was mixed with distilled water in a ratio 1:6 $(\mathrm{m} / \mathrm{V})$. The first experiment was performed to select an ultrasound-assisted extraction time. Samples were treated at $25^{\circ} \mathrm{C}$ for 15,30 and 45 min in an ultrasonic bath (model DT $255 \mathrm{H}$; Bandelin Electronic, Berlin, Germany) at a constant frequency of $50 \mathrm{kHz}$ and power of $160 \mathrm{~W}$. The most effective ultrasound-assisted extraction time from prior studies was selected. Next, the extraction by ultrasound combined with stirring for 15, 30 and $45 \mathrm{~min}$ at room temperature was further investigated. The homogenate was centrifuged (Sorvall RC-5C Plus; Thermo Fisher Scientific, Willmington, DE, USA) at $10000 \times g$ and $25^{\circ} \mathrm{C}$ for $30 \mathrm{~min}$. Then the total phenolic content of samples was evaluated as described below. Concentrations of all tested mango peel extracts were expressed as equivalent mass (in g, on dry mass basis) of mango peel per $\mathrm{mL}$ of solvent (distilled water).

\section{Determination of total phenolic content}

Total phenolic content in mango peel extract was determined using the Folin-Ciocalteu method (17). Briefly, $50 \mu \mathrm{L}$ of the diluted sample (or standard gallic acid solution) were added to $1950 \mu \mathrm{L}$ of distilled water and $250 \mu \mathrm{L}$ of Folin-Ciocalteu reagent solution, and then $750 \mu \mathrm{L}$ of $7 \%$ sodium carbonate were added after $6 \mathrm{~min}$. After incubation at room temperature for $2 \mathrm{~h}$ in the dark, the absorbance of the reaction was measured at $765 \mathrm{~nm}$ by spectrophotometer GENESYS $10 \mathrm{~S}$ (Thermo Fisher Scientific, Waltham, MA, USA). Gallic acid was used as a standard, and the results were expressed in milligrams of gallic acid equivalents (GAE) per $100 \mathrm{~g}$ of mango peel (dry mass basis).

\section{Browning inhibition}

The potatoes were peeled and then blended with mango peel extract or commercial inhibitors (citric acid, ascorbic acid, or sodium disulfite at the concentration of $20 \mathrm{mg} / \mathrm{L}$ ) at ratio 2:1 $(\mathrm{m} / \mathrm{V})$ for $20 \mathrm{~s}$. Sample colour values were measured using a colorimeter (CM-3500D; Konica Minolta, Ramsey, NJ, USA) after $0,1,2,3,4,5$ and $6 \mathrm{~h}$ of storage at room temperature. The browning value of samples at each storage time was calculated using the following equation:

$$
\text { Browning value }=\left(\Delta L^{*} / L_{0}^{*}\right) \cdot 100
$$

where $\Delta L^{*}$ is equal to $L_{0}^{*}-L^{*}, L^{*}$ is the lightness value at a selected time and $L_{0}^{*}$ is the initial lightness (18). Similarly, browning inhibition (in \%) was calculated as follows (19):

Browning inhibition $=($ Browning value control - Browning value $_{\text {inhibitor }} \cdot 100 /$ Browning value $_{\text {control }}$

\section{Polyphenol oxidase inhibition}

\section{PPO preparation}

The preparation of PPO from potato flesh was modified from the method of Galeazzi et al. (20) as follows: potato flesh (100 g) was blended in a blender (34B299; Waring) for $20 \mathrm{~s}$ with $100 \mathrm{~mL}$ of cold $0.1 \mathrm{M}$ sodium phosphate buffer $(\mathrm{pH}=6.6)$ containing $0.5 \%$ Triton X-100 and $1 \%$ polyvinylpyrrolidone. The homogenate was then centrifuged (Sorvall RC-5C Plus; Wilmington, DE, USA) at $15000 \times g$ at $4{ }^{\circ} \mathrm{C}$ for $30 \mathrm{~min}$. The supernatant was filtered through a regular cheese cloth, then the extract was collected at $4{ }^{\circ} \mathrm{C}$ and referred to as a crude enzyme. 
PPO activity assay

PPO activity was estimated by the modified method of Lee (21) as follows. Briefly, $1.0 \mathrm{~mL}$ of $0.2 \mathrm{M}$ catechol (as the substrate) in $0.05 \mathrm{M}$ sodium phosphate buffer, $\mathrm{pH}=6.6$, was mixed with $1 \mathrm{~mL}$ of distilled water and $0.9 \mathrm{~mL}$ of $0.05 \mathrm{M}$ sodium phosphate buffer, $\mathrm{pH}=6.6$, then incubated for $30 \mathrm{~s}$. After that, $0.1 \mathrm{~mL}$ of crude enzyme was added and gently mixed. Its absorbance was rapidly measured every $10 \mathrm{~s}$ for $1 \mathrm{~min}$ at $420 \mathrm{~nm}$ using a spectrophotometer (GENESYS 10S; Thermo Fisher Scientific). One unit of PPO activity was defined as the amount of enzyme that caused an increase in the absorbance at $420 \mathrm{~nm}$ by $0.001 / \mathrm{min}$ at $25^{\circ} \mathrm{C}, \mathrm{pH}=6.6$.

Evaluation of mango peel extract and various antibrowning agents on PPO inhibition

The effect of mango peel extract (as an equivalent to $0.04 \mathrm{~g} / \mathrm{mL}$ mango peel on dry mass basis) and antibrowning agents (citric and ascorbic acids including sodium disulfite) at a final concentration of $20 \mathrm{mg} / \mathrm{L}$ on potato PPO activity was tested with the same method of PPO activity determination by adding each inhibitor ( $1 \mathrm{~mL}$ ) instead of distilled water. The inhibition (in \%) was calculated as described by Chaisakdanugull et al.(22):

Inhibition=[(activity of control-activity of inhibitor)/ activity of control] 100

\section{HPLC-DAD analyses of phenolic compounds}

Phenolic compounds were separated using Waters HPLC (Waters, Milford, Ireland) equipped with Empower ${ }^{\mathrm{TM}} 2$ software, a model 600 controller gradient pump, a Waters model 2707 autosampler and a Waters model 2998 diode array detector. The HPLC column was Hypersil ODS (4.6 mm×250 $\mathrm{mm}$ i.d., $5 \mu \mathrm{m}$; Agilent, Amsterdam, the Netherlands), with a $4.0 \mathrm{~mm} \times 4 \mathrm{~mm}$ i.d., $5 \mu \mathrm{m}$ Hypersil ODS guard column (Agilent, Darmstadt, Germany). The mobile phase was $1 \%$ (by volume) acetic acid in methanol (eluent $A$ ) and $1 \%$ (by volume) acetic acid in water (eluent $B$ ). The following solvent gradients were applied: $10-35 \%$ A (10 min), 35-42 \% A (15 min), 42-75\% A (10 min), $75-75 \%$ A (5 min) and 75 to $10 \%$ A (10 min). The injection volume used for all samples was $10 \mu \mathrm{L}$ at a flow rate of $1 \mathrm{~mL} / \mathrm{min}$. The UV/Vis detection was recorded at $280 \mathrm{~nm}$ for gallic, protocatechuic and ellagic acids and at $370 \mathrm{~nm}$ for mangiferin (modified from Li et al. (23)).

\section{The inhibitory effect of phenolic compounds from mango peel extract on $P P O$}

To confirm the effect of the major phenolic compounds found in mango peel extract on PPO activity inhibition, ellagic, gallic and protocatechuic acids and mangiferin were prepared at the same concentration as the mango peel extract from the HPLC analysis. The effects of these phenolic compounds were assayed for potato polyphenol oxidase inhibition as described above.

\section{Inhibition kinetics of mango peel extract on potato PPO}

The inhibition kinetics of mango peel extract on potato PPO was determined according to the modified method of Kubglomsong and Theerakulkait (19) by monitoring the PPO activity at substrate (catechol) concentrations of $0.025-0.2 \mathrm{M}$. Data were plotted as 1/v against 1/[S] (Lineweaver-Burk plot). To specify the type of mango peel extract inhibition on potato PPO, four mango peel extract concentrations: 0, 0.01, 0.02 and $0.04 \mathrm{~g} / \mathrm{mL}$ were tested using $0.2 \mathrm{M}$ catechol as substrate, again using Lineweaver-Burk plots.

\section{Statistical analyses}

Analyses were all done in triplicate. Statistical significance was assessed using a univariate analysis of variance with SPSS v. 17 (24). Significant differences $(p<0.05)$ among treatments were detected using Duncan's multiple range test (19).

\section{RESULTS AND DISCUSSION}

\section{Ultrasound-assisted extraction of phenolic compounds from mango peel extract}

Mango peel extract was extracted by blending with liquid nitrogen and using ultrasound-assisted extraction for 15, 30 and $45 \mathrm{~min}$. The total phenolic compound content as GAE on dry mango peel mass basis was the highest $(972 \mathrm{mg} / 100$ g) when using a 15-minute ultrasonic treatment. It was more productive than treatments for 30 and $45 \mathrm{~min}$. When using extraction times of 15 and $30 \mathrm{~min}$, the total phenolic content (972 and $939 \mathrm{mg} / 100 \mathrm{~g}$ ) was not significantly different, but it was higher than with extraction time of $45 \mathrm{~min}(\mathrm{p}<0.05)(885$ $\mathrm{mg} / 100 \mathrm{~g}$ ). This might be due to the destruction of phenolic compounds by ultrasound with increasing extraction time. The mango peel extract blended with liquid nitrogen as a freezing agent was useful for controlling enzymatic browning of the mango peel. The ultrasonic processing was vigorous enough to cause damage to cells and increase the release of cell content, leading to increased total phenolic yield. Altemimi et al. (25) reported that exposure to ultrasound could increase the total phenolic compound content in peach and pumpkin extracts. Ultrasound also effectively extracted phenolic compounds from orange (26) and pomegranate peels (27).

The total phenolic content of mango peel extract obtained by ultrasound for 15 min in combination with stirring for 15 min was the highest compared to the extraction with ultrasound for 15 min combined with stirring for 30 and 45 min, and ultrasound only for $15 \mathrm{~min}$ (control). The mass fractions of mango peel extract phenolics obtained by ultrasound for $15 \mathrm{~min}$ in combination with stirring for 15, 30 and $45 \mathrm{~min}$ were 972,939 and $885 \mathrm{mg} / 100 \mathrm{~g}$, respectively $(\mathrm{p}<0.05$; data not shown), while their mass fraction in the control (extracted by ultrasound only) was $880 \mathrm{mg} / 100 \mathrm{~g}$. This is similar to the extraction by ultrasound for 15 min combined with stirring for $45 \mathrm{~min}$ ( $p>0.05$ ). The concentration of phenolic compounds 
decreased with increasing time of stirring and extraction. This might be due to the breakdown of active phenolic compounds (28).

\section{Effects of mango peel extract and various antibrowning agents on potato puree browning}

From our previous research, we found that mango peel extract inhibited enzymatic browning of potato puree to a higher degree than of banana puree (29). Therefore, potato was chosen for further study. The $L^{*}$ results of potato puree treated with mango peel extract were compared with those when a commercial antibrowning agent was added (citric acid, ascorbic acid, or sodium disulfite) by testing them at a final concentration of $20 \mathrm{mg} / \mathrm{L}$ (Fig. 1a). The $L^{*}$ values of potato puree treated with mango peel extract were higher than those of treated with $20 \mathrm{mg} / \mathrm{L}$ of citric acid and stored for 3-6 $h(p<0.05)$. The $L^{*}$ values of potato puree treated with mango peel extract were higher than those when treated with $20 \mathrm{mg} / \mathrm{L}$ ascorbic acid and stored for 3 and $4 \mathrm{~h}(\mathrm{p}<0.05)$. Additionally, $L^{*}$ values of puree samples treated with $20 \mathrm{mg} / \mathrm{L}$ sodium disulfite were higher than those when treated with ascorbic or citric acid (final concentration of $20 \mathrm{mg} / \mathrm{L}$ ) and stored for 5 and $6 \mathrm{~h}(\mathrm{p}<0.05)$. However, after storage for 2 to $4 \mathrm{~h}, \mathrm{~L}^{*}$ values of potato puree treated with sodium disulfite were slightly higher than of the puree treated with mango peel extract $(p>0.05)$. After $6 \mathrm{~h}$ of storage, $L^{*}$ values of the puree treated with mango peel extract, ascorbic acid, citric acid and sodium disulfite were $45,40,38$ and 36 , respectively, showing that mango peel extract was more effective in potato puree browning inhibition than ascorbic or citric acid.

Fig. $1 \mathrm{~b}$ shows the browning values of potato puree mixed with various antibrowning agents after storage at room temperature for up to $6 \mathrm{~h}$. Values for potato puree treated with mango peel extract were lower than of samples treated with ascorbic or citric acid (final concentration $20 \mathrm{mg} / \mathrm{L}$ ) at storage times of 3 to $6 \mathrm{~h}(\mathrm{p}<0.05)$. Mango peel extract treated potato puree exhibited slightly lower browning values, roughly similar to those after treatment with $20 \mathrm{mg} / \mathrm{L}$ ascorbic acid after storage for $2 \mathrm{~h}$ ( $\mathrm{p}>0.05$ ). Moreover, samples treated with ascorbic acid had slightly lower browning values than samples treated with citric acid after storage for 3-6 h. Potato puree treated with $20 \mathrm{mg} / \mathrm{L}$ sodium disulfite had the lowest browning values after storage for 5 and $6 \mathrm{~h}$. Browning values of potato puree treated with sodium disulfite, mango peel extract, ascorbic and citric acid after $6 \mathrm{~h}$ of storage were 39, 44,47 and 51, respectively. The results indicate that mango peel extract could decrease browning of potato puree during storage more than other commercial antibrowning agents.

Nicoli et al. (30) reported that a decrease in the hue angle indicated the changes of colour from yellow to orange and a decrease in $L^{*}$ value also indicated darkening of the colour. Fig. 1c shows that hue angles of potato puree treated with mango peel extract were larger than those when treated with ascorbic or citric acid (final concentration $20 \mathrm{mg} / \mathrm{L}$ ) after storage for 2-6 h $(p<0.05)$. Potato puree treated with $20 \mathrm{mg} / \mathrm{L}$
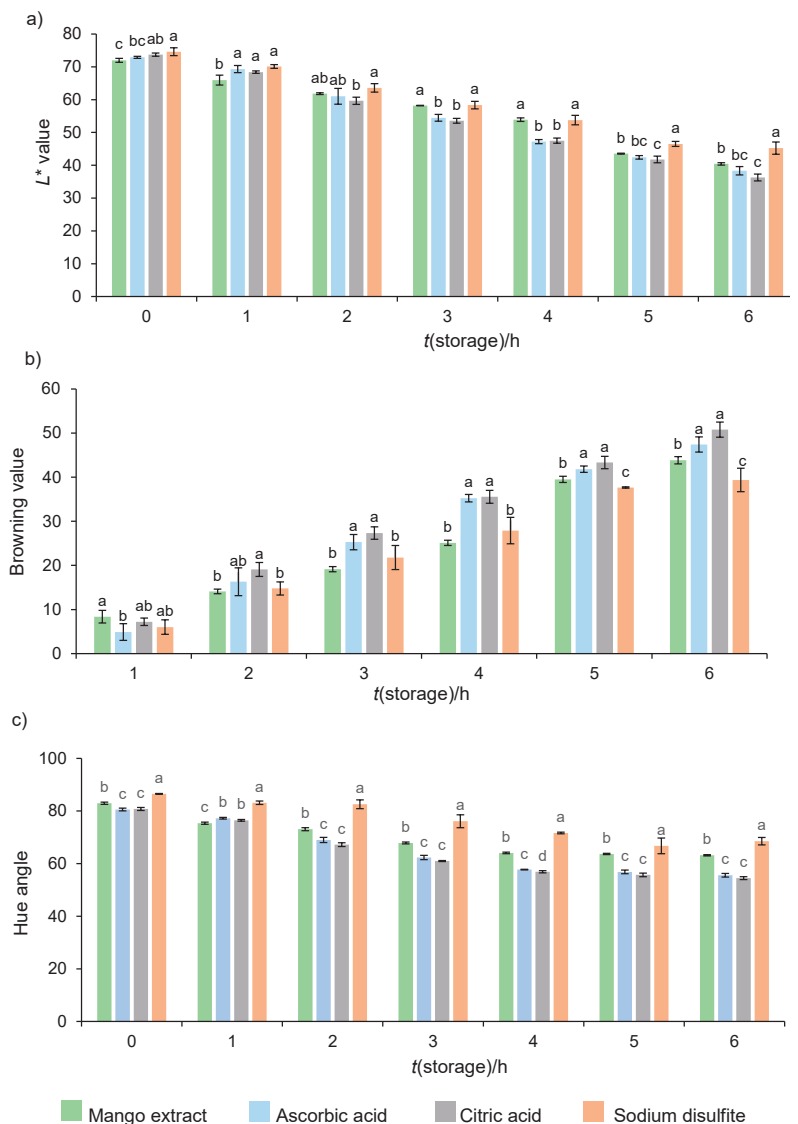

Fig. 1. Results for: a) $L^{*}$ values, b) browning values $\left(\left(\Delta L^{*} / L_{0}^{*}\right) \cdot 100\right)$ and c) hue angle of potato puree blended with mango peel liquid nitrogen powder extract $(\gamma=0.04 \mathrm{~g} / \mathrm{mL})$ and various antibrowning agents (ascorbic acid, citric acid and sodium disulfite) at $\gamma=20 \mathrm{mg} / \mathrm{L}$ and storage time of $0-6 \mathrm{~h}$ at $25^{\circ} \mathrm{C}$. Mean values with different letters are significantly different $(p<0.05)$ for the same storage time

ascorbic acid had slightly higher hue angle value, similar to that from the treatment with $20 \mathrm{mg} / \mathrm{L}$ citric acid after storage for 1, 2, 3, 5 and $6 \mathrm{~h}$. Additionally, hue angles for potato puree treated with $20 \mathrm{mg} / \mathrm{L}$ of sodium disulfite were larger than those when treated with mango peel extract, ascorbic or citric acid after all storage times $(69,63,56$ and 55 , respectively; $\mathrm{p}<0.05)$. From the browning values, $L^{*}$ values and hue angles, it can be concluded that mango peel extract had higher antibrowning effect on potato puree than citric or ascorbic acid, but lower than sodium disulfite. Sukhonthara and Theerakulkait (31) reported that rice bran extract inhibited enzymatic browning of potato puree more than the samples treated with ascorbic or citric acid (final concentration $20 \mathrm{mg} / \mathrm{L}$ ). However, sodium disulfite was determined to be the most effective inhibitor of potato PPO.

\section{Effects of mango peel extract and various antibrowning agents on potato polyphenol oxidase}

The potato PPO inhibition by mango peel extract $(0.04 \mathrm{~g} /$ $\mathrm{mL}$ ) was much higher than by other antibrowning agents (citric and ascorbic acids, and sodium disulfite at a final concentration of $20 \mathrm{mg} / \mathrm{L}$ ), with inhibition equal to $62 \%$, compared 
to 10 and $6 \%$ for citric and ascorbic acid, respectively. Sodium disulfite showed the highest potato PPO inhibition. Sukhonthara and Theerakulkait (31) reported that rice bran extract combined with either ascorbic or citric acid increased the inhibition of enzymatic browning in potato. Duangmal and Owusu Apenten (32) found that sodium disulfite had the highest inhibitory effect on potato PPO, because sulfite reacts with the disulfide bonds in PPO and leads to inactivation and change of its tertiary structure.

\section{Kinetic study}

The inhibition kinetics of mango peel extract on potato PPO was analysed with Lineweaver-Burk plots as shown in Fig. 2. The results show that mango peel extract exhibited a competitive inhibitory effect on potato PPO by using catechol as a substrate. Maisuthisakul and Gordon (2) reported that mango seed kernel extract was also a competitive inhibitor, confirmed by its constant $v_{\max }$ value. The structure of most competitive inhibitors is similar to that of the substrate. Nevertheless, Lou et al. (33) found that the compound $3^{\prime}, 5^{\prime}$-di-C- $\beta$-glucopyranosylphloretin from calamondin peel is competitive inhibitor since the $B$ ring of the 4-hydroxy group closely resembles the structure of the substrate. 3-Hydroxyphloretin isolated from Formosan apple acted as a competitive inhibitor and exhibited reduced tyrosinase activity (34).

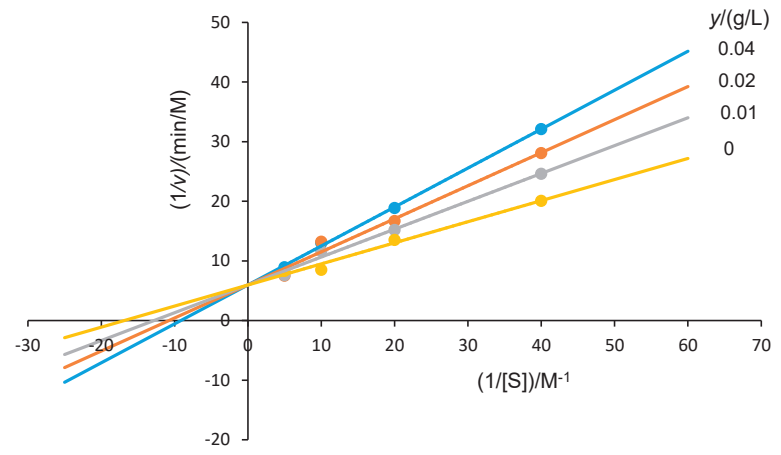

Fig. 2. Lineweaver-Burk plots ( $v=$ reaction rate $(M / m i n)$ and $[S]=$ equilibrium concentration of substrate $(M))$ for the inhibition of potato polyphenol oxidase by mango peel liquid nitrogen powder extract

The inhibition percentage was plotted against the concentration of the inhibitor to determine the amount of mango peel extract needed for $50 \%$ inhibition $\left(\mathrm{IC}_{50}\right)$ of potato PPO activity. In this research, the $I C_{50}$ value was estimated to $0.3 \mathrm{mg} / \mathrm{mL}$ from the plots of concentration versus the inhibition percentage. Other researchers also reported the $I C_{50}$ values of longan fruit extract (2.9-3.2 mg/mL) (35), and immature calamondin peel extract $(0.87 \mathrm{mg} / \mathrm{mL})$ (33) for PPO activity inhibition. Therefore, this result indicated that mango peel extract has a strong inhibitory activity that could inhibit the PPO activity at a low concentration.

\section{Effects of various phenolic acids from mango peel extract on potato PPO inhibition determined by HPLC}

The phenolic compounds in mango peel extract (including ellagic, gallic and protocatechuic acids and mangiferin) were measured using HPLC analysis. A standard chromatogram with the chemical structure of these compounds is shown in Fig. 3. Table 1 shows that the mango peel extract had the highest concentration of mangiferin, followed by ellagic, gallic and protocatechuic acids (220, 105, 71 and $13 \mu \mathrm{g} /$ $\mathrm{mL}$, respectively). Ajila et al. (36) found that the phenolic compounds found in the peel of Badami variety of mango were quercetin, mangiferin, syringic and ellagic acids, and pentoside. The peel of Raspuri mango variety contained ferulic, gallic, protocatechuic and syringic acids, rutin, quercetin and kaempferol (37). The role of phenolic compounds as possible

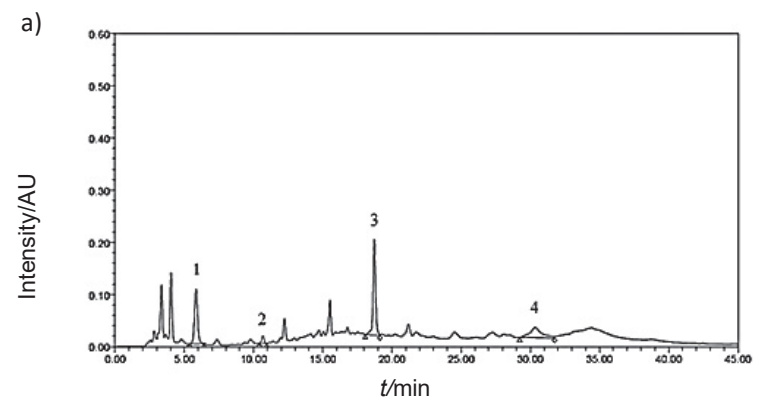

b)
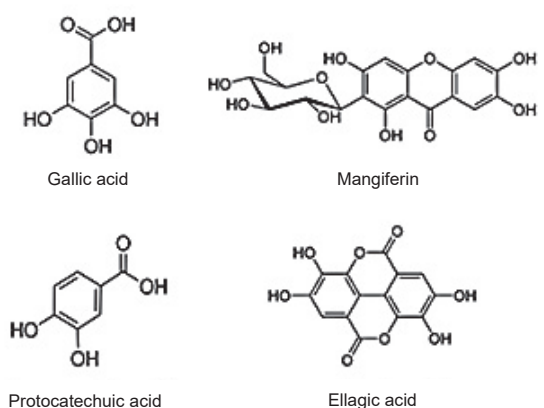

Fig. 3. Chromatogram of phenolic compounds from: a) mango peel liquid nitrogen powder extract identified by HPLC. 1=gallic acid, $2=$ protocatechuic acid, 3 =mangiferin and $4=$ =ellagic acid, and b) chemical structure of phenolic compounds in the mango peel extract

Table 1. Concentrations of phenolic compounds separated by HPLC from mango peel liquid nitrogen powder extract and their inhibition of potato polyphenol oxidase activity

\begin{tabular}{ccccc} 
Mango peel extract & Gallic acid & Protocatechuic acid & Mangiferin & Ellagic acid \\
$\gamma /(\mu \mathrm{g} / \mathrm{mL})$ & $(70.5 \pm 8.9)^{\mathrm{c}}$ & $(13.1 \pm 2.9)^{\mathrm{d}}$ & $(220.2 \pm 8.5)^{\mathrm{a}}$ & $(104.9 \pm 11.6)^{\mathrm{b}}$ \\
Inhibition/\% & $(77.1 \pm 2.0)^{\mathrm{a}}$ & $(77.1 \pm 2.0)^{\mathrm{a}}$ & $(80.2 \pm 0.5)^{\mathrm{a}}$ & $(13.9 \pm 4.0)^{\mathrm{b}}$ \\
\hline
\end{tabular}

Mean values with different letters in the same row are significantly different $(p<0.05)$ 
inhibitors of PPO activity was experimentally examined using model systems in which each of the phenolic compounds was prepared at the same concentration as the mango peel extract for HPLC analysis, as shown in Table 1. The relative inhibitory activities on potato PPO were in the following order: mangiferin=gallic acid=protocatechuic acid $>$ ellagic acid $(p<0.05)$. Mangiferin exhibited slightly higher potato PPO inhibition than gallic and protocatechuic acids. Ellagic acid had the lowest inhibitory effect on potato PPO $(p<0.05)$. Mangiferin and gallic and protocatechuic acids have two hydroxyl groups in the structure (Fig. 3b). This structure is an analogue of the diphenolase substrate, catechol. It may inhibit the activity of PPO through a competitive inhibition. Nagendra Prasad et al. (38) reported that the inhibitory activity of an enzyme may depend on the hydroxyl group of the phenolic compound in litchi seed extracts. These groups were able to form hydrogen bonds with the active site of the enzyme, leading to decreased enzymatic activity. The hydroxyl group of some inhibitors can bind to the active site of an enzyme resulting in steric hindrance or a change in the structure of the enzyme. Mangiferin and gallic and protocatechuic acids also have a conjugated structure made up of a benzene ring or a carboxyl group. Thus, this structure may contribute steric hindrance to the enzyme active site. Qiu et al.(39) reported that 4-hydroxycinnamic acid could inhibit diphenolase activity since it is a large conjugated compound consisting of a benzene ring, an ethylenic linkage and a carboxyl group that provides steric hindrance to the enzyme active site. Protocatechuic acid from black rice bran extract also had inhibitory effect on enzymatic browning (40). Macrae and Duggleby (41) reported that the $p$-coumaric, ferulic and cinnamic acids exhibited the most potent inhibitory effect against potato PPO. These acids from full-fatted and commercially defatted rice bran extracts exhibited inhibitory effects against enzymatic browning on potato and apple PPO (10).

\section{CONCLUSIONS}

Extraction of phenolic compounds from mango peel liquid nitrogen powder with ultrasonication for $15 \mathrm{~min}$ combined with stirring for 15 min showed a high total phenolic compound content and strong potato polyphenol oxidase (PPO) inhibitory effect. The extract was effective in inhibiting browning in potato puree during storage for 1-6 h. Our kinetic inhibition study of potato PPO by mango peel liquid nitrogen powder extract revealed competitive inhibition. The major phenolic compounds present in mango peel extract were mangiferin and gallic, protocatechuic and ellagic acids, as determined by HPLC. Mangiferin and gallic and protocatechuic acids had higher inhibitory effects on potato PPO activity than ellagic acid at the concentration present in the extract. This indicated that mangiferin and gallic and protocatechuic acids play an important role in potato PPO inhibition. Therefore, mango peel extract has a potential for use as a natural antibrowning agent in potato puree.

\section{ACKNOWLEDGEMENTS}

This work was supported by a grant from the Graduate School Kasetsart University, Kasetsart University Research and Development Institute (KURDI), Bangkok, Thailand. We express our sincere gratitude to the Peace Canning (1958) Co. Ltd., Chiangmai, Thailand, for providing mango peel for this research.

\section{ORCID ID}

C. Theerakulkait @ https://orcid.org/0000-0002-1385-0229

\section{REFERENCES}

1. Jahurul MHA, Zaidul ISM, Ghafoor K, Al-Juhaimi FY, Nyam KL, Norulaini NAN, et al. Mango (Mangifera indica L.) by-products and their valuable components: A review. Food Chem. 2015;183:173-80.

https://doi.org/10.1016/j.foodchem.2015.03.046

2. Maisuthisakul P, Gordon MH. Antioxidant and tyrosinase inhibitory activity of mango seed kernel by product. Food Chem. 2009;117(2):332-41. https://doi.org/10.1016/j.foodchem.2009.04.010

3. Kim H, Kim H, Mosaddik A, Gyawali R, Ahn KS, Cho SK. Induction of apoptosis by ethanolic extract of mango peel and comparative analysis of the chemical constitutes of mango peel and flesh. Food Chem. 2012;133(2):416-22. https://doi.org/10.1016/j.foodchem.2012.01.053

4. Ajila CM, Naidu KA, Bhat SG, Prasada Rao UJS. Bioactive compounds and antioxidant potential of mango peel extract. Food Chem. 2007;105(3):982-8.

https://doi.org/10.1016/j.foodchem.2007.04.052

5. Manach C, Williamson G, Morand C, Scalbert A, Rémésy C. Bioavailability and bioefficacy of polyphenols in humans. I. Review of 97 bioavailability studies. Am J Clin Nutr. 2005; 81(1):230S-42.

https://doi.org/10.1093/ajcn/81.1.230S

6. Watanabe T, Kuribara H, Mishima T, Kikuchi H, Kodama T, Futo $S$, et al. New qualitative detection methods of genetically modified potatoes. Biol Pharm Bull. 2004;27(9):1333-9. https://doi.org/10.1248/bpb.27.1333

7. Sapers GM, Douglas Jr FW, Bilyk A, Hsu AF, Dower HW, Garzarella L, Kozempel M. Enzymatic browning in atlantic potatoes and related cultivars. J Food Sci. 1989;54(2):362-5. https://doi.org/10.1111/j.1365-2621.1989.tb03081.x

8. Boonsiripiphat $\mathrm{K}$, Theerakulkait C. Extraction of rice bran extract and some factors affecting its inhibition of polyphenol oxidase activity and browning in potato. Prep Biochem Biotechnol. 2009;39(2):147-58.

https://doi.org/10.1080/10826060902800817

9. Kaewka K, Portongkum K, Theerakulkait C. Preparation of ultrafiltered rice bran extract and some factors affecting its browning inhibition in potato puree. Prep Biochem 
Biotechnol. 2009;39(4):360-71.

https://doi.org/10.1080/10826060903209505

10. Sukhonthara S, Kaewka K, Theerakulkait C. Inhibitory effect of rice bran extracts and its phenolic compounds on polyphenol oxidase activity and browning in potato and apple puree. Food Chem. 2016;190:922-7. https://doi.org/10.1016/j.foodchem.2015.06.016

11. Ali HM, El-Gizawy AM, El-Bassiouny RE, Saleh MA. The role of various amino acids in enzymatic browning process in potato tubers, and identifying the browning products. Food Chem. 2016;192: 879-85.

https://doi.org/10.1016/j.foodchem.2015.07.100

12. Saisung $P$, Theerakulkait $C$. Inhibitory effect of pineapple shell extract and its ultrafiltered fractions on polyphenol oxidase activity and browning in fresh-cut banana slices. CYTA-J Food. 2011;9(1):37-42.

https://doi.org/10.1080/19476330903515472

13. Busch JM. Enzymic browning in potatoes: A simple assay for a polyphenol oxidase catalysed reaction. Biochem Educ. 1999;27(3):171-3.

https://doi.org/10.1016/S0307-4412(99)00033-3

14. Zhou L, Liu W, Xiong Z, Zou L, Chen J, Liu J, Zhong J. Different modes of inhibition for organic acids on polyphenoloxidase. Food Chem. 2016;199:439-46.

https://doi.org/10.1016/j.foodchem.2015.12.034

15. McEvily AJ, lyengar R, Otwell WS. Inhibition of enzymatic browning in foods and beverages. Crit Rev Food Sci Nutr. 1992;32(3):253-73.

https://doi.org/10.1080/10408399209527599

16. Theerakulkait C, Saisung P. Effect of pineapple shell extracts on browning in fresh vegetable and fruit puree and slices. Kasetsart J (Nat Sci). 2006;40:182-8.

17. Zou Y, Chang SK, Gu Y, Qian SY. Antioxidant activity and phenolic compositions of lentil (Lens culinaris var. Morton) extract and its fractions. J Agric Food Chem. 2011;59(6):2268-76. https://doi.org/10.1021/jf104640k

18. Labuza TP, Lillemo JH, Taoukis PS. Inhibition polyphenol oxidase by proteolytic enzymes, 'Killer Enzymes'. Proceedings of the 20th Symposium of the International Federation of Fruit Juice Producers, Scientific Technical Commission; 1990 May 15-16, Paris, France; 1990. pp. 1-15.

19. Kubglomsong S, Theerakulkait C. Effect of rice bran protein extract on enzymatic browning inhibition in potato puree. Int J Food Sci Technol. 2014;49(2):551-7. https://doi.org/10.1111/ijfs.12336

20. Galeazzi MAM, Sgarbieri VC, Constantinides SM. Isolation, purification and physicochemical characterization of polyphenoloxidases (PPO) from a dwarf variety of banana (Musa cavendishii L.). J Food Sci. 1981;46(1):150-5. https://doi.org/10.1111/j.1365-2621.1981.tb14551.x
21. Lee HS. Tyrosinase inhibitors of Pulsatilla cernua root-derived materials. J Agric Food Chem. 2002;50(6):1400-3. https://doi.org/10.1021/jf011230f

22. Chaisakdanugull C, Theerakulkait C, Wrolstad RE. Pineapple juice and its fractions in enzymatic browning inhibition of banana [Musa (AAA group) Gros Michel]. J Agric Food Chem. 2007;55(10): 4252-7. https://doi.org/10.1021/jf0705724

23. Li H, Cao D, Yi J, Cao J, Jiang W. Identification of the flavonoids in mungbean (Phaseolus radiatus L.) soup and their antioxidant activities. Food Chem. 2012;135(4):2942-6.

https://doi.org/10.1016/j.foodchem.2012.07.048

24. SPSS Statistics for Windows, v. 17.0, SPSS Inc., Chicago, IL, USA; 2008.

25. Altemimi A, Watson DG, Choudhary R, Dasari MR, Lightfoot DA, Ultrasound assisted extraction of phenolic compounds from peaches and pumpkins. PLoS ONE. 2016;11(2): e0148758.

https://doi.org/10.1371/journal.pone.0148758

26. Khan MK, Abert-Vian M, Fabiano-Tixier AS, Dangles O, Chemat F. Ultrasound-assisted extraction of polyphenols (flavanone glycosides) from orange (Citrus sinensis L.) peel. Food Chem. 2010;119(2):851-8.

https://doi.org/10.1016/j.foodchem.2009.08.046

27. Kazemi M, Karim R, Mirhosseini H, Abdul Hamid A. Optimization of pulsed ultrasound assisted technique for extraction of phenolics from pomegranate peel of Malas variety: Punicalagin and hydroxybenzoic acids. Food Chem. 2016; 206:156-66.

https://doi.org/10.1016/j.foodchem.2016.03.017

28. Liyana-Pathirana C, Shahidi F. Optimization of extraction of phenolic compounds from wheat using response surface methodology. Food Chem. 2005;93(1):47-56. https://doi.org/10.1016/j.foodchem.2004.08.050

29. Jirasuteeruk C, Theerakulkait C. Effect of different varieties of mango peel extracts on enzymatic browning inhibition in banana puree. Proceedings of the 4th International Conference on Engineering and Natural Science (ICENS) - Summer Session; 2016 July 12-14; International Community House, Kyoto, Japan; 2016. pp. 634-44.

30. Nicoli MC, Anese M, Severini C. Combined effects in preventing enzymatic browning reactions in minimally processed fruit. J Food Qual. 1994;17(3):221-9.

https://doi.org/10.1111/j.1745-4557.1994.tb00145.x

31. Sukhonthara S, Theerakulkait C. Inhibitory effect of rice bran extract on polyphenol oxidase of potato and banana. Int J Food Sci Tech. 2012;47(3):482-7.

https://doi.org/10.1111/j.1365-2621.2011.02867.x

32. Duangmal K, Owusu Apenten RK. A comparative study of polyphenoloxidases from taro (Colocasia esculenta) and potato (Solanum tuberosum var. Romano). Food Chem. 1999; 64(3):351-9.

https://doi.org/10.1016/S0308-8146(98)00127-7 
33. Lou SN, Yu MW, Ho CT. Tyrosinase inhibitory components of immature calamondin peel. Food Chem. 2012;135(3):1091-6. https://doi.org/10.1016/j.foodchem.2012.05.062

34. Lin YP, Hsu FL, Chen CS, Chern JW, Lee MH. Constituents from the Formosan apple reduce tyrosinase activity in human epidermal melanocytes. Phytochemistry. 2007;68(8):1189-99. https://doi.org/10.1016/j.phytochem.2007.02.001

35. Rangkadilok N, Sitthimonchai S, Worasuttayangkurn L, Mahidol C, Ruchirawat M, Satayavivad J. Evaluation of free radical scavenging and antityrosinase activities of standardized longan fruit extract. Food Chem Toxicol. 2007;45(2):328-36. https://doi.org/10.1016/j.fct.2006.08.022

36. Ajila CM, Jaganmohan Rao L, Prasada Rao UJS. Characterization of bioactive compounds from raw and ripe Mangifera indica L. peel extracts. Food Chem Toxicol. 2010;48(12): 3406-11.

https://doi.org/10.1016/j.fct.2010.09.012

37. Ajila CM, Prasada Rao UJS. Mango peel dietary fibre: Composition and associated bound phenolics. J Funct Foods.
2013;5(1):444-50.

https://doi.org/10.1016/j.jff.2012.11.017

38. Nagendra Prasad K, Yang B, Yang S, Chen Y, Zhao M, Ashraf $M$, Jiang $Y$. Identification of phenolic compounds and appraisal of antioxidant and antityrosinase activities from litchi (Litchi sinensis Sonn.) seeds. Food Chem. 2009;116(1):1-7. https://doi.org/10.1016/j.foodchem.2009.01.079

39. Qiu L, Chen QH, Zhuang JX, Zhong X, Zhou JJ, Guo YJ, Chen QX. Inhibitory effects of a-cyano-4-hydroxycinnamic acid on the activity of mushroom tyrosinase. Food Chem. 2009; 112(3):609-13.

https://doi.org/10.1016/j.foodchem.2008.06.021

40. Miyazawa M, Oshima T, Koshio K, Itsuzaki Y, Anzai J. Tyrosinase inhibitor from black rice bran. J Agric Food Chem. 2003;51(24):6953-6.

https://doi.org/10.1021/jf030388s

41. Macrae AR, Duggleby RG. Substrates and inhibitors of potato tuber phenolase. Phytochemistry. 1968;7(5):855-61. https://doi.org/10.1016/S0031-9422(00)84843-8 